\title{
HVMANITAS
}

\section{Los nombres de Dioniso en Las Bacantes de Eurípides y el lenguaje retórico de Tiresias}

\author{
Autor(es): $\quad$ Encinas Reguero, M. Carmen \\ Publicado por: $\begin{aligned} & \text { Faculdade de Letras da Universidade de Coimbra, Instituto de Estudos } \\ & \text { Clássicos }\end{aligned}$ \\ URL \\ persistente: \\ URI:http://hdl.handle.net/10316.2/22917 \\ DOI: $\quad$ DOI:http://dx.doi.org/10.14195/2183-1718_63_6
}

Accessed : $\quad$ 26-Apr-2023 13:29:47

A navegação consulta e descarregamento dos títulos inseridos nas Bibliotecas Digitais UC Digitalis, UC Pombalina e UC Impactum, pressupõem a aceitação plena e sem reservas dos Termos e Condições de Uso destas Bibliotecas Digitais, disponíveis em https://digitalis.uc.pt/pt-pt/termos.

Conforme exposto nos referidos Termos e Condições de Uso, o descarregamento de títulos de acesso restrito requer uma licença válida de autorização devendo o utilizador aceder ao(s) documento(s) a partir de um endereço de IP da instituição detentora da supramencionada licença.

Ao utilizador é apenas permitido o descarregamento para uso pessoal, pelo que o emprego do(s) título(s) descarregado(s) para outro fim, designadamente comercial, carece de autorização do respetivo autor ou editor da obra.

Na medida em que todas as obras da UC Digitalis se encontram protegidas pelo Código do Direito de Autor e Direitos Conexos e demais legislação aplicável, toda a cópia, parcial ou total, deste documento, nos casos em que é legalmente admitida, deverá conter ou fazer-se acompanhar por este aviso.

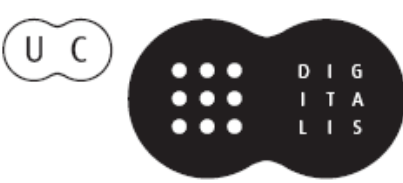


humanitas

Vol. LXIII

2011 


\title{
LOS NOMBRES DE DIONISO EN LAS BACANTES DE EURÍPIDES Y EL LENGUAJE RETÓRICO DE TIRESIAS
}

\author{
M. Carmen Encinas Reguero \\ Universidad del País Vasco / Euskal Herriko Unibertsitatea
}

\section{Resumo}

En Bacantes el dios Dioniso es llamado, sobre todo, Dioniso, Bromio y Baco. En mi opinión, Dioniso es el nombre neutro del dios, Bromio se relaciona con su epifanía y Baco con su aspecto más destructor. El modo distinto de nombrar al dios tiene repercusiones en la caracterización de los personajes y, sobre todo, de Tiresias.

Palabras clave: Eurípides, Bacantes, Dioniso, Baco, Tiresias.

\begin{abstract}
In Euripides'Bacchae there are mainly three appellatives used to name Dionysos, namely, Dionysos, Bromios and Bacchos. In my opinion, Dionysos is the neutral name of the god, Bromios relates to his epiphany and Bacchos to his most destructive aspect. This distinction in the way of naming the god has implications for the characterization of the characters and mainly of Teiresias.

Key words: Euripides, Bacchae, Dionysos, Bacchos, Teiresias.

${ }^{1}$ Este trabajo ha contado con la financiación del Ministerio de Ciencia e Innovación a través de un proyecto de investigación subvencionado (FFI2009-10130/ FILO) y constituye una ampliación de la comunicación titulada "De los nombres de Dioniso en Las Bacantes de Eurípides", leída en el Coloquio Internacional Redefinir Dioniso: Mito y Culto (Madrid, 3-6 febrero 2010). Agradezco a la Dra. M. Quijada (Universidad del País Vasco/Euskal Herriko Unibertsitatea) la ayuda que me ha prestado con la atenta lectura de este trabajo y sus sugerencias al respecto.
\end{abstract}


Sabido es que el dios Dioniso recibe nombres distintos en las diferentes fuentes de que disponemos. Este trabajo se va a centrar en los nombres que el dios recibe a lo largo de Bacantes de Eurípides, la única tragedia griega conservada que tiene como protagonista a Dioniso².

Para ello se van a valorar, en primer lugar, el significado y las connotaciones de los epítetos utilizados en este drama para sustituir a Dioniso, el nombre principal del dios. Esos epítetos son esencialmente Bromio, que en la obra se vincula con la epifanía y las características positivas de la divinidad, y Baco, un epíteto vinculado tradicionalmente con la manía dionisíaca y que, en mi opinión, Eurípides utiliza en Bacantes para aludir, sobre todo, al carácter ctónico del hijo de Sémele.

Para demostrarlo se analizan en un segundo apartado todos los pasajes de Bacantes en que Dioniso es nombrado con cualquiera de sus epikléseis. Este análisis no solo confirma las connotaciones expuestas, sino que, además, pone de manifiesto las diferencias que existen entre los personajes con respecto a la denominación del dios y, por lo tanto, su distinta actitud frente a la divinidad. Pero, sobre todo, el análisis pone al descubierto el carácter peculiar del modo en que Tiresias se refiere al dios en la obra. Esto último conduce a un apartado final, que añade un punto a considerar en la debatida cuestión del "inapropiado" y excesivamente retórico lenguaje utilizado por el adivino en la obra.

\section{Los nombres de Dioniso: significado e interpretación propuesta}

Dioniso es denominado en Bacantes fundamentalmente de tres maneras, a saber, Dioniso, Bromio y Baco. Excepcionalmente se encuentran también otros dos nombres: Íaco (v. 725) y Ditirambo (v. 526).

El primero de éstos, Íaco (Íacchos), es la personificación del grito ritual que se profería en determinados momentos del culto en los misterios de Eleusis ${ }^{3}$. Parece que el grito ritual íacche se entendió como un vocativo, del que se derivó el nominativo Íacchos, que se identificó gradualmente con Dioniso ${ }^{4}$. Íaco se presenta como personificación del grito ritual en

${ }^{2}$ Parece que el tema de Dioniso no fue raro y que otros dramaturgos antes que Eurípides escribieron obras relacionadas con su mito. Cf. Dodds 1944: xxvxxx, Oranje 1984: 124-130, Hose 2008: 202-203.

${ }^{3}$ Cf. Burkert 1972: 307-308, Versnel 1972: 26-29.

${ }^{4}$ La interpretación de Íacchos como un nominativo derivado de íacche y que en principio no tenía nada que ver con Dioniso está bastante generalizada. Sin 
Heródoto 8.65, que podría ser el testimonio más antiguo conservado5. El término es utilizado también en Sófocles, Antígona 1152, donde Íaco es un epíteto de Dioniso en su función de líder o choragós de las ménades ${ }^{6}$. En Ranas de Aristófanes (v. 320, 324-325, 341, 399, 404, 410, 416), sin embargo, Íaco parece ser una divinidad independiente de Dioniso? ${ }^{7}$ En $\mathrm{Ba}$ cantes esta denominación es utilizada en el primer relato de mensajero (v. 725 ) en un pasaje en el que se describen las ceremonias báquicas y, sin duda, el epíteto alude al dios del vino ${ }^{8}$.

Por su parte, el término ditirambo (dithýrambos) alude a una ejecución coral en honor a Dioniso (cf. Platón, Leyes 700b) '. $^{9}$ pero también a un miembro del thíasos dionisíaco y al propio Dioniso. Si el nombre designa originariamente al dios y de ahí pasa a la canción en su honor o, por el contrario, designa la canción y solo secundariamente al dios, es una cuestión debatida en la que no voy a entrar. En el Etymologicum Magnum, s.v. ${ }^{10}$ el término se explica como ó dì $\theta u ́ g \alpha \zeta \varepsilon \beta \varepsilon \beta \eta x \omega ́ s$ ("el que dos veces cruzó la puerta del nacimiento"). Sin duda, Eurípides tiene este significado popular en mente cuando utiliza este nombre en Bacantes, pues el pasaje en que lo hace alude al dios en el momento en que pasa de Sémele a Zeus (v. 526). No obstante, y aunque la etimología del nombre no estáclara, filológicamente

embargo, se han propuesto interpretaciones distintas a la luz de algunos testimonios. Así, Versnel 1972: 37-38, defiende que la conexión con Dioniso existía ya antes de la personificación del dios Íaco. Además, puesto que el grito íacche está vinculado con Eleusis, Versnel plantea una hipótesis, a saber, que Pisístrato favoreciera la propagación de los elementos dionisíacos para ganarse la adhesión de las clases bajas y utilizara para ello precisamente un elemento de los misterios eleusinos, en los que se sabe que el tirano estaba muy interesado.

${ }^{5}$ Es imposible saber cuándo exactamente redactó Heródoto su magna obra. Ahora bien, el pasaje de Acarnienses 525 ss. de Aristófanes, obra representada por primera vez en 425 a.C., permite pensar que fue con suficiente antelación a esa fecha como para que el público reconociese la alusión. Esto sitúa la redacción de Heródoto en una fecha probablemente no muy lejana a la de Antígona, que de manera generalizada se data en 442-441 a.C.

${ }^{6}$ Por su vinculación con Eleusis, Henrichs 1990: 266, considera que la alusión a Íaco es utilizada por Sófocles para pagar su tributo al Dioniso ático.

${ }^{7}$ Cf. Versnel 1972: 23-24. Cf. nota 4.

${ }^{8}$ Dodds 1944: 157, considera inapropiado que el nombre Íaco sea utilizado en referencia a Dioniso por parte de seguidores tebanos.

${ }^{9}$ Cf. Pickard-Cambridge 1962, $2^{\mathrm{a}}$ ed.: 1-7.

${ }^{10}$ Utilizo la edición de Gaisford 1848 (repr. 1962). 
se puede descartar la explicación que proporciona el Etymologicum Magnum $^{11}$.

Ahora bien, las denominaciones más usuales de Dioniso en Bacantes son, como ya he dicho, Dioniso, Bromio y Baco. Dioniso es el nombre principal del dios. Bromio (Brómios) es un apelativo muy común, que hace referencia al fuego y al rayo vinculados a su nacimiento. Diodoro Sículo (4.5.1-2) explica los diferentes nombres del dios y con respecto a Bromio

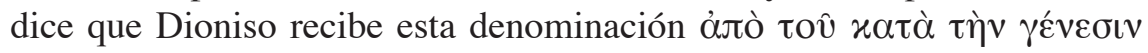

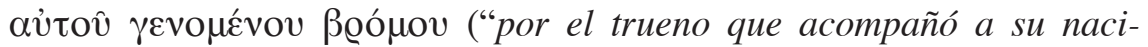
miento" "12). Esa misma conexión se encuentra también en el escolio a $\mathrm{Il}$.

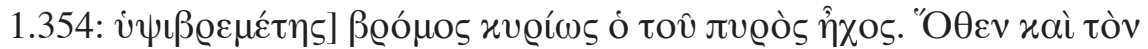

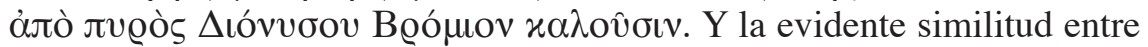
el epíteto Brómios y el nombre del trueno (brómos) permite suponer que este significado del nombre del dios era algo asumido de manera general.

Más complejo e interesante, sin embargo, resulta establecer el significado preciso del otro epíteto que recibe Dioniso en Bacantes: Baco. A partir del s. V a.C. y rara vez antes de esa fecha ${ }^{13}$ Dioniso es llamado con frecuencia Baco (Bácchos) y sus seguidores bácchoi o bácchai ${ }^{14}$. Ahora bien, el dios es denominado también con el adjetivo bácchios y, de hecho, es llamado así con más frecuencia que con el término Bácchos. En concreto, en Bacantes Dioniso es llamado trece veces bácchios y solo dos veces

${ }^{11}$ Cf. Dodds 1944: 136, Pickard-Cambridge 1962, 2a ed: 7-9.

${ }^{12}$ Para Diodoro Sículo utilizo la traducción de Torres Esbarranch 2004.

${ }^{13}$ Según el trabajo leído por M. A. Santamaría en el Coloquio Internacional Redefinir Dioniso, los pasajes literarios más antiguos en los que el epíteto Bácchos o sus derivados se refieren a Dioniso son los que siguen: Bácchos: S. OT 211, E. Hipp. 560, IT , 163, IA 1061, Ba. 623, 1020, Protesilaus fr. 646a, 15, Rh. 972, Trag. Adesp. fr. 204 (Kannich-Snell), Evenus, fr. 2.1 (West, Gentili-Prato), Carmina Popularia 851 (b) 1 (PMG); baccheîos: h.Pan 46, S. OT 1105, Hdt. 4.79.2, 4.79.12, E. Cyc. 73, Ar. Ra. 1259; bácchios: S. fr. 1130, Ant 154, E. Ion 550, 552, 553, 716, IT 953, Ba. 68, 195, 225, 366, 529, 605, 632, 998, 1089, 1124, 1145, 1153, 1189, Cyc. 9, 38, 143, 156, 429, 446, 454, 519, 521, 575, 709, Oeneus, fr. 562.1 (Kannicht), Hypsipyla fr. 759a, 1627 (Kannicht), fr. 896.1 (Kannicht), Moschion fr. 6.24 (Snell), Timotheus fr. 780.4 (Hordern), Ar. Ach. 263.

${ }^{14}$ El término bácchos significa "rama" y se usaba especialmente en el lenguaje religioso para aludir a las ramas sagradas que se portaban en los ritos (cf.

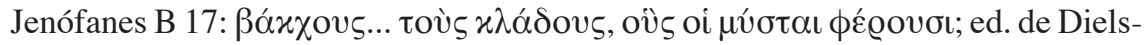
-Kranz 1951, 6 ed. (repr. 1992)). Los bácchoi recibían este nombre, entonces, por las ramas que portaban; cf. West 1978: 374-375. 
Bácchos $^{15}$. La pregunta, entonces, es por qué, si Bácchos es el epíteto del dios, se prefieren derivativos de ese término para referirse a él. Según West, el derivativo ha de entenderse como "dios de los bácchoi" ". De hecho, ya

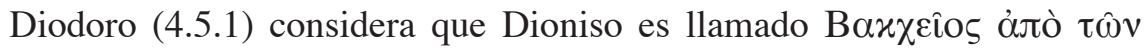

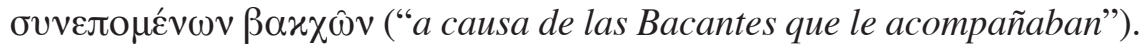
Cuando el dios es llamado Bácchos, puede ser porque cuenta como uno de ellos, como su éxarchos. En todo caso, tanto Bácchos como sus derivativos no son un nombre propio, sino que han de ser entendidos como algunos de los numerosos epítetos o invocaciones de Dioniso, que se emplean como sustitutos del nombre del dios ${ }^{17}$.

Además, desde $I l$. 6.132 Dioniso es definido en términos de locura. Homero lo denomina mainómenos y la tradición que sigue conecta precisamente los términos Bácchos, Baccheîos y los epítetos relacionados del dios con la manía dionisíaca ${ }^{18}$. La evidencia más temprana es Heródoto 4.79, que presenta a Dioniso Baccheîos como un dios que induce la manía en los hombres y preside los misterios ${ }^{19}$. Y en la tragedia griega también, como Schlesier ${ }^{20}$ ha explicado, la locura violenta se clasifica fundamentalmente en relación con Dioniso Baco. No ha de sorprender, entonces, encontrar este significado del epíteto Baco en Bacantes, donde ese término es utilizado en varias ocasiones en relación con el éxtasis o los ritos menádicos.

Ahora bien, ese significado del epíteto Baco, que, sin duda, existe en Bacantes, no es, sin embargo, el significado principal del término en la obra. Con más frecuencia el epíteto es utilizado en alusión al carácter ctónico del dios. Esta vinculación implícita entre el epíteto Baco y el carácter ctónico de Dioniso se encuentra establecida de manera explícita en el primer verso del Himno órfico 53, donde Bácchos es el equivalente de

${ }^{15}$ Bácchos: v. 623, 1020; bácchios: vv. 67-68, 195, 225, 366, 528-529, 605, 632, 998, 1089, 1124, 1145, 1153, 1189.

${ }^{16}$ Cf. West 1978: 374.

${ }^{17}$ Cf. Jeanmaire 1991 (1951, $1^{\text {a }}$ ed.): 57.

${ }^{18}$ Cf. Schlesier 1993: 93.

${ }^{19}$ Graf 1985: 286, explica también que "Dionysos Bakcheus ist der Gott des dionysischen Taumels. Alle Wörter vom Stamme $\beta \alpha x \chi$-bezeichnen, wenn sie nicht unmittelbar auf den Kult des Dionysos verweisen, allgemein Raserei, Wahnsinn und Ekstasse".

${ }^{20}$ Cf. Schlesier 1993: 101: "Violent frenzy of several kinds, even when caused by distinct divine forces, is classified in tragedy under the sign of Dionysus Bacchos and is fundamentally related to him". 
$\chi \theta$ óvıos $\Delta$ ıóvvбos. Determinar en qué medida dicha identificación estaba extendida o era asumida por la audiencia es difícil. No obstante, creo que el hecho de encontrarse en obras distintas y, sobre todo, de una manera tan clara en el Himno órfico 53 apunta a que la identificación no debía de sorprender y seguramente, aunque secundaria en el significado de Baco, más fácilmente identificable con el término "bacante" y consiguientemente con los ritos menádicos asociados, el público la percibiría.

Dioniso es un dios ambiguo. Sus principales características lo definen como dios del vino, del menadismo, del culto a los muertos y del teatro. En definitiva, estos cuatro elementos o ámbitos marcan una supresión de los límites habituales del ser humano ${ }^{21}$. En Bacantes Eurípides no hace ninguna alusión al aspecto de Dioniso como dios vinculado al mundo infernal. Hay alusiones al vino, al menadismo e implícitamente al teatro, como han puesto de relieve muchos estudios metateatrales de este drama ${ }^{22}$. En ningún momento, sin embargo, se alude a la otra función esencial de Dioniso, la de dios de ultratumba. Ahora bien, tal vez pudiera haber algo de ello implícitamente en la simple denominación del dios como Baco, que alude a su carácter ctónico.

Si se analiza el reparto de los tres nombres principales de Dioniso a lo largo de la tragedia, se observa que, frente a un reparto más o menos uniforme del término Dioniso, los epítetos Bromio y Baco predominan en diferentes partes de la tragedia. Bacantes se puede dividir en dos partes separadas por el v. 810. Este verso, formado por una simple interjección, interrumpe el diálogo y el metro, y marca el fin del intento de persuasión del dios a Penteo y el comienzo de la venganza ${ }^{23}$. Pues bien, el epíteto Bromio es utilizado con más frecuencia en la primera parte de la tragedia, mientras que, por el contrario, Baco, está más concentrado en la segunda.

En la primera parte de la tragedia el nacimiento de Dioniso es un tema constantemente aludido. Esta cuestión se presenta en numerosos momentos, desde distintos puntos de vista, en relación con diferentes personajes; se racionaliza; se presenta de forma lírica; una y otra vez la obra aborda la

${ }^{21}$ Como Diller 1955: 456, escribe, la atracción del culto a Dioniso reside "in der Befreiung aus den Grenzen des Ich".

${ }^{22}$ Cf., por ejemplo, Segal 1982: 215-271, Segal 1985, Bierl 1991: 186-218 o Radke 2003. También hay quien se opone a una interpretación metateatral de Bacantes, como, por ejemplo, Kullmann 1993.

23 "From now on he [Dioniso] is cruel, ruthless, and utterly unscrupulous in the method of securing his end"; cf. Grube 1935: 42. 
cuestión. En la segunda parte de la tragedia, sin embargo, el tema desaparece. Pues bien, el tratamiento reiterado del nacimiento del dios coincide con una mayor incidencia del epíteto Bromio, mientras que, cuando el tema deja de suscitarse, el epíteto se hace mucho más infrecuente ${ }^{24}$.

En la segunda parte de la tragedia, en cambio, cuando el tema principal es la venganza, cobra protagonismo el epíteto Baco. Esencialmente Dioniso es un dios olímpico, pero tiene características ctónicas ${ }^{25}$. Pues bien, ya Rohde advirtió la tendencia a suprimir el nombre o utilizar eufemismos en relación a divinidades ctónicas ${ }^{26}$. El ejemplo más manido al respecto es el de Euménides frente a Erinias. Según Henrichs, "Götter ohne Namen, deren positive oder negative Epitheta die fehlenden Götternamen ersetzen müssen, sind im chthonischen Bereich die Regel' 27 . Un ejemplo que proporciona este autor es Deméter, cuyo nombre se suprime o se utiliza indirectamente cuando lo que designa es la cólera de la diosa. Pues bien, en mi opinión, Eurípides utiliza en Bacantes el epíteto Baco como sustituto de Dioniso, sobre todo cuando alude a las características ctónicas del dios. Y el hecho de que se puedan encontrar ejemplos similares con respecto a otras divinidades, como han argumentado Rohde y Henrichs, hace pensar que la designación consistente del Dioniso destructor por medio del epíteto Baco en Bacantes sería bien entendida por la audiencia.

\section{Los nombres de Dioniso en Bacantes: demostración de la interpretación propuesta y diferencias entre los personajes}

Para demostrar la interpretación anteriormente expuesta se va a poner de relieve a continuación el modo en que cada uno de los personajes del drama se refiere a Dioniso. En este sentido el personaje más relevante, y,

${ }^{24}$ Cf. Hamilton 1974: 147.

${ }^{25}$ Ya Platón, Leyes 828c constata la división de culto entre los dioses olímpicos y los ctónicos. Al respecto, cf. también Isócrates 5.117: “a los dioses que nos originan bienes les llamamos Olímpicos, mientras que los que se han encargado de las desgracias y castigos tienen nombres peores"; traducción de Guzmán Hermida, 1980. Sobre el Dioniso ctónico, cf. Jeanmaire 1991 (1951, 1ª ed.): 268-278.

${ }^{26}$ Cf. Rohde 1921, 7a/8 a ed.: 206-212. Obsérvese que Isócrates 5.117 (cf. nota 25 ) evita dar un nombre a los dioses ctónicos. Sobre la cuestión de la falta de nombres o el empleo de eufemismos para designar a dioses ctónicos, cf. también Henrichs 1991.

${ }^{27}$ Cf. Henrichs 1991: 180. 
por lo tanto, con el que es más oportuno comenzar, es el propio Dioniso, ya que él, además de ser el dios en persona, funciona dentro de la tragedia en cierta medida como un narrador externo ${ }^{28}$.

Dioniso habla en su calidad de dios en el prólogo y en la éxodos, cuando se presenta como deus ex machina. En esos momentos se refiere a sí mismo con el nombre de Dioniso (v. $2^{29}, 27,1341$ ), que parece ser el nombre neutro de la divinidad. En el resto de la tragedia Dioniso se presenta bajo la apariencia de un extranjero seguidor del dios, que se refiere a éste en tercera persona. En el episodio segundo la conversación gira en torno a los atributos, los ritos y la cualidad divina del dios y el nombre que el extranjero utiliza es también invariablemente Dioniso (v. 466, 496, 517). Lo mismo sucede en la última parte del episodio tercero (v. 825, 849, 860). Al final del episodio cuarto, sin embargo, el extranjero, en la última mención que hace del dios en el momento en que Penteo sale de la ciudad rumbo al Citerón, anuncia su victoria y la de Bromio (v. 978). Más adelante volveré sobre este significativo pasaje.

No obstante, donde mayores variaciones se encuentran con respecto al nombre del dios es en la primera parte del episodio tercero. Al comienzo de ese pasaje el Coro escucha la voz del dios y se habla de un terremoto, del incendio del palacio y del fuego sobre la tumba de Sémele. Cuando posteriormente el extranjero entra en escena, se encuentra con las ménades lidias del Coro aterrorizadas. El extranjero se dirige a ellas y alude al miedo que han sentido por Baco ("Habéis oído, según parece, a Baco, cuando sacudió el palacio de Penteo", v. 605-606). Por primera vez el extranjero utiliza el epíteto Baco y lo hace precisamente cuando alude a un hecho, el terremoto, que es la manifestación del poder más terrible y destructor del dios.

A continuación, en la narración de los hechos que se han desarrollado dentro del palacio el extranjero utiliza el nombre de Baco en dos ocasiones (v. 623, 632). En ambas el nombre se relaciona con el poder destructor de Dioniso ("En ese momento llegó Baco, sacudió el palacio y prendió fuego

${ }^{28}$ Dioniso tiene una autoridad narrativa que lo acerca al nivel del poeta; $\mathrm{cf}$. MacLeod 2006: 580-581.

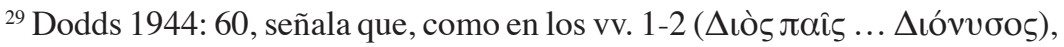
también en otros pasajes del drama el nombre de Dioniso aparece junto al genitivo

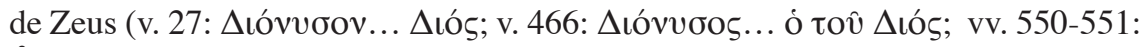

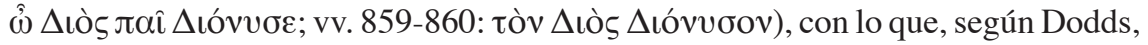
Eurípides puede estar sugiriendo la relación etimológica entre ambos nombres. 
en la tumba de su madre", vv. 622-624; "Además de esto, Baco le causó otro daño: echó abajo su palacio", vv. 632-633).

Por el contrario, Bromio no tiene que ver con el aspecto destructor del dios, sino con su epifanía. Cuando el extranjero cuenta que el dios hace aparecer una figura, a la que Penteo trata de matar, el nombre que ese dios recibe es precisamente Bromio ("Y entonces Bromio... suscitó un fantasma en el patio", vv. 629-630). De hecho, es revelador el pasaje del primer relato de mensajero, en el que Dioniso es llamado Bromio y también Íaco. Se ha propuesto que el grito íacche, del que deriva el epíteto Íaco, funciona, como algunos otros gritos rituales, en el contexto de una epifanía divina, relacionada generalmente, aunque no siempre, con Dioniso ${ }^{30}$. Pues bien, si esto es así, la presencia de Íaco junto al epíteto Bromio enfatiza el significado de epifanía de este momento.

Así pues, en la escena del "milagro del palacio" en el episodio tercero de Bacantes se advierte perfectamente la diferencia entre los tres principales nombres que recibe Dioniso en este drama, a saber, Dioniso, con un valor neutro, Bromio, asociado a la epifanía, y Baco, ligado al aspecto destructor del dios.

Si esta diferencia se admite, entonces se pueden entender mejor dos pasajes en los que el extranjero, teniendo como interlocutor a Penteo, llama Bromio al dios (v. 790, 978). En el primero de estos pasajes el extranjero, en su intento de persuasión, advierte al monarca de que no debe levantar sus armas contra el dios (vv. 787-791). El epíteto Bromio (v. 790) evita aquí las connotaciones de amenaza que el término Baco, según lo expuesto, pudiera implicar. En el segundo de esos pasajes, mencionado anteriormente, el extranjero anuncia la victoria de Bromio (v. 978) en el momento en que se dispone a conducir a Penteo hacia el Citerón, donde habrá de morir. También aquí el empleo del epíteto Bromio puede deberse al intento de remarcar ante Penteo las características positivas del dios ocultando su faceta más terrible. Es decir, el extranjero utiliza ante Penteo el epíteto del dios que se relaciona con la manifestación positiva de su poder. Pero, además, irónicamente el empleo por parte del extranjero del epíteto Bromio puede estar apuntando implícitamente a su identidad real. No hay que olvidar que el extranjero, aunque habla bajo esa apariencia, es realmente Dioniso y toda su participación en la obra implica para la audiencia externa una gran epifanía.

${ }^{30}$ Cf. Versnel 1972: 26-27. 
Veamos ahora cómo se refiere el Coro al dios. La párodos celebra a Dioniso como dios del éxtasis y pone de relieve la felicidad que confiere practicar su culto. Cualquier indicio de salvajismo o brutalidad se halla ausente $^{31}$. Durante dicha párodos el Coro pronuncia con frecuencia el nombre del $\operatorname{dios}^{32}$. Lo llama alternativamente Dioniso (v. 72, 81, 85, 119, 134, 155) o Bromio (v. 66, 84, 87, 11533, 141). Sólo una vez (vv. 67-68) utiliza el epíteto Baco. En el episodio primero el Corifeo alude en una ocasión a Bromio (v. 329) y en el stásimon primero Bromio es el único nombre que el dios recibe (v. 375, 413). En ese stásimon el Coro celebra la moderación; Dioniso es asociado con la pólis y por eso quizás es celebrado como dios del vino, elemento esencial para la ciudad (cf. Platón, Leyes 649d-e).

El segundo stásimon presenta la oposición entre Dioniso y Penteo y concretamente se centra en el nacimiento del primero y la ascendencia del segundo. Dioniso sigue siendo el dios griego y civilizado del primer stásimon, pero empiezan a emerger aspectos más salvajes suyos. En este stásimon Bromio y Dioniso, aunque predominan, no son las únicas designaciones utilizadas, pues el Coro llama al dios también Baco (vv. 528-529) y Ditirambo (v. 526). Ahora bien, estos versos del Coro en los que el dios no es llamado ni Bromio ni Dioniso forman parte precisamente de un discurso directo atribuido a Zeus. El nombre de Ditirambo posiblemente es utilizado en referencia al doble nacimiento de Dioniso, como antes se ha dicho. El término Baco hace alusión al aspecto más terrible de Dioniso y aquí en boca de Zeus parece implicar que es este dios el que garantiza el poder destructor de su hijo.

En el episodio tercero el Coro llama Bromio al dios durante los versos en los que escucha la voz de éste. Esto es lo más adecuado, dado el carácter

${ }^{31}$ Sobre la párodos y los stásima corales en Bacantes, cf. Arthur 1972.

${ }^{32}$ En Bacantes existen en realidad dos Coros: uno formado por las ménades lidias que acompañan al extranjero-Dioniso y que forman el Coro físico de la tragedia y otro formado por las mujeres de Tebas, a las que el dios ha enloquecido y que se encuentran en el Citerón. Dioniso habla a través de las primeras, pero actúa a través de las segundas. Ambos grupos de mujeres son denominados ménades o bacantes. Según Henrichs 1982: 146, el término habitual en el culto es el de bacante, mientras que ménade es un término poético.

${ }^{33}$ Sobre la lectura de este verso y los problemas de interpretación que ha generado, cf. Henrichs 1984. 
de epifanía de la escena ${ }^{34}$. Más adelante, el Corifeo utiliza el término neutro Dioniso (v. 777).

En el stásimon cuarto el proceso de venganza de Dioniso ya se ha desatado. El Coro adopta una postura mucho más agresiva y la brutalidad de la oda es manifiesta. En ese stásimon las ménades lidias se refieren al dios únicamente con el nombre de Baco (v. 998, 1020). En el episodio quinto, al conocer el desenlace de la muerte de Penteo, el Coro alude al dios como Dioniso (v. 1037), al referirse simplemente al hijo de Zeus, y como Bromio (v. 1031), al apelar a la manifestación del dios ("iSoberano Bromio, te muestras como un gran dios!", v. 1031). No obstante, en el stásimon quinto, cuando el Coro celebra con un canto de victoria la venganza del dios, vuelve a llamarlo Baco (v. 1153). Así pues, en el stásimon cuarto y quinto el Coro se refiere al dios sólo con el epíteto Baco. Estos dos stásima son los que rodean al relato de mensajero en el que se describe la muerte del rey.

Es decir, el Coro utiliza siempre los nombres de Dioniso y Bromio, salvo en un discurso directo atribuido a Zeus y en los dos últimos stásima, en los que el único nombre del dios es $\mathrm{Baco}^{35}$. En esos dos stásima, la actitud inicial del Coro ha cambiado por completo y el apelativo de Baco se corresponde con el contenido destructor de los cantos.

Cadmo menciona el nombre del dios tan solo en tres ocasiones y cada vez lo hace de un modo distinto. En primer lugar utiliza el nombre de Dioniso para aludir al dios como hijo de Sémele (v. 182). Después, y en conexión con sus rituales y con el éxtasis menádico, lo llama Baco (v. 195). Pero el pasaje más llamativo está en la éxodos, donde Cadmo se refiere al dios como Bromio (v. 1250), a pesar de que lo hace aludiendo a su aspecto destructor (";Cómo el dios a nosotros, de modo justo, pero en exceso, nos ha destruido, el soberano Bromio, nacido en esta familia!", vv. 12491250). Es quizás su deseo de evitar la censura al dios, en parte porque es miembro de su familia, lo que explica que Cadmo evite en ese contexto el término Baco, que métricamente encajaría de igual manera. De hecho, es una característica de Cadmo su deseo de defender la divinidad de Dioniso

${ }^{34}$ Como Wildberg 2002: 149, ha dicho, toda la tragedia de Bacantes es en realidad una monumental epifanía del dios, que, sin embargo, solo es reconocida como tal por la audiencia externa. Algunos pasajes, sin embargo, revisten la forma de epifanía también para la audiencia interna.

${ }^{35}$ La otra excepción está en los vv. 67-68, donde el dios es llamado bácchios, pero en vinculación con los ritos menádicos. 
precisamente porque éste forma parte de su familia (cf. vv. 181-183, 333336). Así pues, no sorprende que Cadmo evite poner de manifiesto las características ctónicas del dios y opte, además, por un significado más benigno del epíteto Baco.

Penteo sólo utiliza dos nombres, a saber, Dioniso y Baco; nunca Bromio. En el episodio primero, cuando se refiere al dios de manera neutra aludiendo exclusivamente a su identidad o su origen o genealogía, utiliza el término Dioniso (v. 220, 242). Luego, cuando se refiere al dios en vinculación con su culto y el éxtasis de las ménades, lo llama Baco (v. 225). Penteo sólo nombra al dios una vez más en la obra. Lo hace en el episodio tercero (v. 652) y utiliza el nombre de Dioniso, en alusión al dios vinculado con el vino. Él no cree en ese dios y tampoco lo reconoce en el extranjero; es coherente, por tanto, que evite el nombre ligado a su epifanía.

En el episodio segundo un sirviente entra en escena para anunciar, de un lado, la captura del extranjero y, de otro, la liberación de las bacantes, previamente apresadas. En su relato explica cómo las bacantes "brincan por las fértiles tierras sagradas invocando al dios Bromio" (vv. 445-446). También el primer mensajero, que narra la situación de las bacantes en el Citerón, así como el sparagmós de los rebaños y el ataque a las poblaciones de Hisias y Eritras, se refiere al dios como Bromio (v. 726), y además como Íaco (v. 725), en el contexto de las celebraciones báquicas. En ambos casos la alusión a Bromio se realiza en un contexto positivo de celebración.

Sin embargo, el segundo mensajero, que acompaña a Penteo y al extranjero en su expedición al Citerón para observar a las bacantes, opta por un nombre distinto para aludir al dios. Cuando se refiere a la voz que se oye instando a la acción a las bacantes, la identifica como la voz de Dioniso (v. 1079). No obstante, la segunda incitación del dios, la que definitivamente da paso a la acción furiosa de las mujeres, es atribuida a Baco (v. 1089). El dios es nombrado en otros dos momentos de la narración y también con el epíteto Baco. Se trata del momento en el que Ágave, poseída por el dios, no reconoce a su hijo y se dispone a dar comienzo al sparagmós (v. 1124) ${ }^{36} \mathrm{y}$ del momento en que, tras esa acción, Ágave regresa feliz al palacio con la cabeza de su hijo invocando al dios (v. 1145).

36 "Maenads and bakkhai, the maddened female followers of Dionysus, are frequently associated in Greek literature with violent death, especially with the murder of their own male offspring"; cf. Schlesier 1993: 97. 
Por último, Tiresias utiliza sólo los nombres de Dioniso y Baco. Utiliza el nombre de Dioniso para aludir a la figura divina elaborada para engañar a Hera, dentro de la explicación racionalista sobre el nacimiento del dios (v. 294). También cuando alude a los atributos y características del dios lo llama así (v. 305, 314). Sin embargo, cuando se refiere al dios en conexión con sus ritos menádicos lo llama Baco (v. 366) ${ }^{37}$. Este pasaje es significativo. Oranje ha puesto en relación este verso con el v. 82, donde el Coro considera dichoso al que sirve a Dioniso. Según él, esta idea es reinterpretada por el adivino, para quien el servicio al dios tiene tintes más $\operatorname{oscuros}^{38}$. El distinto significado que el servicio a Dioniso tiene para el Coro y Tiresias, que, sin duda, como Oranje ha puesto de relieve, existe y es revelador, va acompañado, además, de un cambio en el nombre del dios, a quien el Coro denomina Dioniso y Tiresias Baco. Es decir, la denominación del dios concuerda con el cambio de significado o, quizás mejor, el cambio en el nombre contribuye a remarcar el diferente significado que el servicio a Dioniso tiene para ambos personajes.

Ahora bien, en el caso de Tiresias lo más llamativo no es el nombre que utiliza para el dios, sino, de un lado, el hecho de que él, como Penteo, aunque defiende la existencia y el poder del dios, también evita el nombre que alude a su epifanía, y, de otro lado, sobre todo, es llamativo el modo en que insistentemente el adivino evita nombrar al dios en modo alguno. En el diálogo inicial con Cadmo, éste se refiere al dios por el nombre, pero Tiresias tanto en ese momento como después, en la discusión con Penteo, utiliza insistentemente la expresión "el dios" (ò Đeós: v. 192, 194, 206,

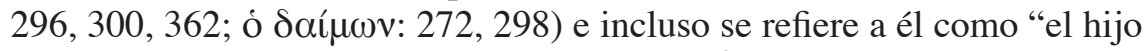
de Sémele" (v. 278) 39 o simplemente "él" (oữos: v. 284; xảxeîvos: v. 321). Esto contrasta con el hecho de que utiliza el nombre de Dioniso por

${ }^{37}$ Hay tres pasajes en el episodio primero en que Dioniso es llamado Baco en vinculación con el éxtasis menádico. Lo hacen Cadmo (v. 195), Penteo (v. 225) y Tiresias (v. 366).

38 Oranje 1984: 40: "He who takes part in the service of Dionysos was

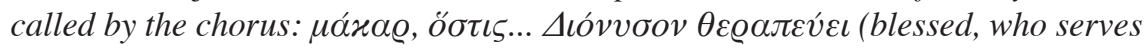
Dionysus) (82), but in Teiresias' mouth this service becomes the compulsion of

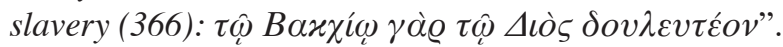

${ }^{39}$ Obsérvese que la ausencia del nombre de Dioniso en este pasaje queda puesta de relieve por el hecho de que Dioniso es comparado con Deméter, a la que sí se nombra (v. 275). 
primera vez precisamente para aludir a la figura fabricada de éter, que realmente no es el dios. La paradoja es evidente.

Tras lo anteriormente expuesto, se puede afirmar que Dioniso parece el nombre neutro de la divinidad; Bromio está en conexión con el nacimiento del dios y su epifanía y alude, sobre todo, a su parte positiva; y Baco, aunque se utiliza en alguna ocasión en alusión al éxtasis menádico inspirado por Dioniso, es empleado, sobre todo, en referencia al dios cuando realiza acciones terribles; es decir, el epíteto Baco representa su parte más negativa. Si se acepta esto, no parece extraño que Penteo renuncie a llamarlo Bromio. Sí que sorprende, en cambio, que lo haga Tiresias. Pero más aún sorprende que Tiresias evite en numerosas ocasiones, como se ha dicho, dar un nombre a la divinidad. Quizás hay que relacionar este hecho con el carácter peculiar que Tiresias tiene en esta tragedia.

\section{Los nombres de Dioniso y el lenguaje retórico de Tiresias}

Bacantes es en términos generales una obra difícil de entender, como se ha asumido en múltiples ocasiones. Aunque los escollos para su comprensión global son numerosos, dos han sido de manera primordial los pasajes concretos que han acaparado la atención de los críticos por la dificultad que plantean en sí mismos y en relación con la comprensión global del drama. En primer lugar, la llamada escena del "milagro del palacio", esto es, el comienzo del episodio tercero, en el que se alude a un incendio y a un terremoto, que según la visión del Coro causa destrozos importantes, pero en función de la reacción de Penteo no resulta siquiera perceptible. Esto ha llevado a numerosas y contrapuestas interpretaciones, en las que aquí no voy a entrar ${ }^{40}$. La segunda cuestión que ha suscitado todo tipo de opiniones tiene que ver con Tiresias y con su peculiar modo de expresión ${ }^{41}$. El problema esencial es que Tiresias es un adivino y, sin embargo, se expresa como un sofista, lo que resulta absolutamente llamativo

${ }^{40}$ Los intérpretes racionalistas no aceptan el "milagro del palacio" y defienden que todo en esa escena se puede explicar sin necesidad de apelar a lo religioso o sobrenatural. Frente a ellos, otro grupo de autores considera que sobre el escenario debía de desarrollarse algún tipo de movimiento que daba sensación de milagro. Al respecto, cf., entre otros, Glover 1929, Norwood 1954: 52-73, Fisher 1992, Winnington-Ingram 1997, 2a ed. (1948, 1ª ed.): 180-185, González Merino 1998.

${ }^{41}$ Sobre el problema que plantea el personaje de Tiresias en Bacantes y las distintas interpretaciones que se han dado al respecto, cf. Gallistl 1979: 5-14. 
y requiere necesariamente de una explicación. No es mi intención en lo que sigue proporcionar una solución a tan compleja cuestión, pero sí creo poder aportar algo a la discusión poniendo de relieve el modo peculiar en que Tiresias utiliza los nombres de Dioniso en la tragedia y la interpretación que, en mi opinión, ello merece.

Es imprescindible partir del hecho de que Tiresias forma parte dentro de la tragedia griega de una tradición, que, sin duda, era conocida por el público. En esa tradición Tiresias es un adivino, que funciona como portavoz entre los humanos de la esfera de los dioses. Esta función, sin embargo, no es necesaria en Bacantes, porque en esa tragedia el dios está personalmente en escena (como dios en el prólogo y la éxodos y disfrazado de extranjero en el resto de la obra) y, por lo tanto, no requiere de portavoz alguno. Esto ha conducido a la afirmación de que el Tiresias de Bacantes, como el de Fenicias, no es necesario, porque el poeta podría haber dicho lo mismo sin él ${ }^{42}$. Sin embargo, Eurípides ha utilizado a Tiresias en lugar de a cualquier otro personaje y le ha dotado de un lenguaje muy peculiar.

Efectivamente, Tiresias se expresa en Bacantes con un lenguaje especialmente retórico, muy propio de la sofística del s. V a.C. y que lo aleja por completo de su rol tradicional ${ }^{43}$. La pregunta que se suscita es por qué Eurípides elige precisamente a este personaje para dotarlo de tal modo de expresión. Si ese lenguaje extremadamente retórico puede llegar a sorprender en la tragedia, mucho más en boca del personaje en el que menos cabría esperarlo. Si Eurípides ha creado esta situación, sin duda, lo ha hecho con un fin determinado.

Pues bien, en ese modo de expresión retórica juega, a mi juicio, un papel relevante la manera peculiar en que Tiresias se refiere a Dioniso. En primer lugar, Tiresias nunca utiliza el epíteto Bromio, que, como he defendido, alude a la epifanía del dios y a su parte positiva. El único otro personaje que hace esto mismo (dejo a un lado al segundo mensajero, que es un personaje menor) es Penteo. En el caso de Penteo puede ser comprensible la elusión del epíteto Bromio, pues Penteo niega al dios; sin embargo, en el caso de Tiresias, que se presenta como seguidor y defensor

${ }^{42}$ Cf. Papadopoulou 2001: 26.

${ }^{43}$ En contraste con el Coro, Tiresias representa la aceptación filosófica e intelectual del dionisismo; cf. Conacher 1967: 62. Incluso cuando Tiresias habla sobre el futuro que le espera a Penteo, dice explícitamente que no habla como profeta (vv. 368-369). Es decir, sus palabras son una deducción humana. Según Grube 1935: 42, esto es porque el destino de Penteo aún no está decidido. 
del dios, resulta llamativo. Aunque explícitamente Tiresias reconoce a Dioniso y lo defiende, implícitamente su modo de nombrar al dios lo vincula de algún modo con el escepticismo y con la falta de comprensión de Penteo.

Pero, además, Tiresias utiliza el nombre de Dioniso por primera vez paradójicamente para referirse a la figura de éter fabricada por Hera (v. 294), que no es realmente el dios. Es decir, la explicación racionalista del adivino busca aparentemente justificar la versión popular y extendida de su doble nacimiento ${ }^{44}$, sin embargo, al utilizar el nombre de Dioniso, que hasta ese momento se ha negado a emplear, para aludir a una figura de éter, Tiresias parece apuntar implícitamente a un cuestionamiento de la identidad real del dios.

Por otra parte, el adivino utiliza sólo una vez el epíteto Baco (v. 366) y lo hace en alusión a los ritos menádicos, al igual que Cadmo (v. 195) y Penteo (v. 225). Él no emplea en ningún momento el epíteto Baco para poner de relieve la faceta destructora del dios. De hecho, en su discurso, una encendida defensa de Dioniso, Tiresias pone de relieve el aspecto civilizador y positivo de esa divinidad. Ahora bien, en este punto hay que llamar la atención nuevamente sobre el hecho de que Tiresias tiende a evitar nombrar en modo alguno al dios.

Decía en el primer apartado de este trabajo que tanto Rohde como Henrichs han puesto de relieve la tendencia a suprimir el nombre o utilizar eufemismos en relación a divinidades ctónicas ${ }^{45}$. Y en el segundo apartado he tratado de demostrar que Baco es precisamente el epíteto utilizado en muchos pasajes de Bacantes para aludir eufemísticamente a Dioniso remarcando su faceta más temible y destructora, propia del ámbito ctónico. Pues bien, en el caso de Tiresias, que una y otra vez evita nombrar a Dioniso, es posible relacionar la elusión del nombre con la tendencia general a hacer eso mismo en el ámbito de las divinidades ctónicas. Esta observación ofrece una explicación a esa rara elusión del nombre del dios que se encuentra insistentemente en las palabras del adivino, pero al mismo tiempo plantea una paradoja, pues el discurso de Tiresias, que explícitamente subraya los

${ }^{44}$ Según Oranje 1984: 47-49, la explicación racionalista de Tiresias es una sátira del poeta a la sofística, pues la versión de Tiresias es tan absurda como la versión popularmente aceptada. Cf. también Diller 1955: 462, Winnington-Ingram 1997, $2^{a}$ ed. (1948, $1^{\text {a }}$ ed.): 50. Por otra parte, "Die Kritik am Seher Teiresias ist ein Motiv, das die Theben-Stücke durchzieht”; cf. Hose 2008: 207.

${ }^{45}$ Cf. nota 26 y 27. 
aspectos positivos de Dioniso y que opta por un significado del epíteto Baco alejado de la vinculación ctónica, implícitamente, a través de la ausencia del nombre del dios, apunta precisamente a ese carácter ctónico.

Es decir, a través de la elusión del epíteto Bromio, que establece una correspondencia entre Tiresias y Penteo, por medio del empleo del nombre de Dioniso utilizado para designar al dios precisamente cuando no es el dios, y al recurrir a la frecuente supresión absoluta de un nombre para el dios, que es un comportamiento característico de quien se refiere a una divinidad ctónica, se llega a una curiosa paradoja, a saber, que el personaje encargado de defender explícitamente al dios (a parte del Coro y del dios mismo, por supuesto), tanto por su función de adivino, que lo vincula con la esfera de los dioses y con una tradición dentro de la tragedia, cuanto por su lenguaje retórico, que le permite realizar una defensa también desde el plano más estrictamente político, ese personaje utiliza un lenguaje que encierra un significado inverso.

El discurso de Tiresias es aparentemente una encendida defensa de Dioniso y de su divinidad. Implícitamente, sin embargo, ese lógos encierra un significado contrario, que apunta a los rasgos ctónicos del dios, a lo más oscuro y destructor de su carácter. Y así, tanto el personaje y la función del adivino, como el lenguaje sofístico quedan cuestionados. Pero, además y sobre todo, Eurípides deja claro que en esta obra nada es necesariamente lo que parece, o, dicho de otro modo, que lo que se ve y se escucha puede no ser realmente lo que sucede o se dice.

No hay duda de que Bacantes es una obra compleja; la más compleja de Eurípides, en mi opinión. Y no hay duda tampoco de que Tiresias, lejos de ser un personaje no necesario, como se ha dicho ${ }^{46}$, es un personaje esencial para comprender el juego de significados y dualidades opuestas que saturan esta tragedia. Y el nombre del dios, una cuestión aparentemente de alcance limitado, se muestra en último término como una guía esencial para descubrir algunos de esos juegos ocultos.

\section{Bibliografía}

Arthur, M. (1972), "The Choral Odes of the Bacchae of Euripides", YCS 22: 145-179.

${ }^{46}$ Cf. nota 42 . 
Bierl, A. F. H. (1991), Dionysos und die griechische Tragödie. Politische und 'metatheatratlische' Aspekte im Text. Tübingen.

BURKerT, W. (1972), Homo Necans. Interpretationen altgriechischer Opferriten und Mythen. Berlin-New York.

Conacher, D. J. (1967), Euripidean Drama. Myth, Theme and Structure. Toronto.

Diels, H., Kranz, W. (1951, 6 ed.), Die Fragmente der Vorsokratiker. 3 Vols. Weidmann (repr. 1992).

Diller, H. (1955), "Die Bakchen und ihre Stellung im Spätwerk des Euripides", Akademie der Wissenschaften und der Literatur in Mainz, Nr. 5: 453-471 (versión inglesa: "Euripides' Final Phase: the Bacchae", in E. Segal (ed.), Oxford Readings in Greek Tragedy. Oxford 1983: 357-369).

Dodds, E. R. (1944), Euripides. Bacchae. Oxford.

FisheR, R. K. (1992), “The 'Palace Miracles' in Euripides' Bacchae: a Reconsideration", AJP 113: 179-188.

GAISFORD, T. (1848), Etymologicum Magnum. Amsterdam (repr. 1962).

Gallistl, B. (1979), Teiresias in den Bakchen des Euripides. Würzburg.

Glover, M. R. (1929), “The Bacchae”, JHS 49: 82-88.

González Merino, J. I. (1998), "La liberación de Dioniso y la destrucción del palacio de Penteo en Las Bacantes de Eurípides (Bacch 576637)", Fortunatae 10: 41-51.

Graf, F. (1985), Nordionische Kulte. Religionsgeschichtliche und epigraphische Untersuchungen zu den Kulten von Chios, Erythrai, Klazomenai und Phokaia. Schweizerisches Institut in Rom.

Grube, G. M. A. (1935), "Dionysos in the Bacchae", TAPhA 66: 37-54.

Guzmán Hermida, J. M. (1980), Isócrates. Discursos II. Madrid.

Hamilton, R. (1974), “Bacchae 47-52: Dionysus' Plan”, TAPhA 104: 139-149.

Henrichs, A. (1982), "Changing Dionysiac Identities", in B. F. Meyer, E.

P. Sanders (eds.), Jewish and Christian Self-Definition. Vol. 3. SelfDefinition in the Greco-Roman World. Philadelphia: 137-160.

Henrichs, A. (1984), "Male Intruders among the Maenads: the so-called Male Celebrant", in H. D. Evjen (ed.), Mnemai. Classical Studies in Memory of Kark K. Hulley. California: 69-91.

Henrichs, A. (1990), "Between Country and City: Cultic Dimensions of Dionysus in Athens and Attica", in M. Griffith y D. Mastronarde (eds.), Cabinet of the Muses. Essays on Classical and Comparative Literature in Honor of Thomas G. Rosenmeyer. Atlanta: 257-277. 
Henrichs, A. (1991), "Namenlosigkeit und Euphemismus: Zur Ambivalenz der chthonischen Mächte im attischen Drama", in H. Hofmann (ed.) (unter Mitarbeit von A. Harder), Fragmenta dramatica. Beiträge zur Interpretation der grieschischen Tragikerfragmente und ihrer Wirkungsgeschichte. Göttingen: 161-201.

Hose, M. (2008), Euripides. Der Dichter der Leidenschaften. München. Jeanmaire, H. (1991), Dionysos. Histoire du culte de Bacchus. Paris (1951, $1^{\mathrm{a}}$ ed.).

Kullmann, W. (1993), "Die 'Rolle' des euripideischen Pentheus. Haben die Bakchen eine 'metatheatralische' Bedeutung?", in G. W. Most, H. Petersmann, A. M. Ritter (eds.), Philanthropia kai Eusebeia. Festschrift für Albrecht Dihle zum 70. Geburtstag. Göttingen: 248-263.

MacLeod, L. (2006), "Marauding Maenads: the first Messenger Speech in the Bacchae", Mnemosyne 59: 578-584.

Norwood, G.. (1954), “The Bacchae and its Riddle”, Essays on Euripidean Drama. London: 52-73.

Oranje, H. (1984), Euripides' Bacchae. The Play and its Audience. Leiden.

Papadopoulou, T. (2001), “The Prophetic Figure in Euripides' Phoenissae and Bacchae", Hermes 129: 21-31.

Pickard-Cambridge, A. (1962, 2a ed.), Dithyramb, Tragedy and Comedy. Oxford.

RAdKe, G. (2003), Tragik und Metatragik. Berlin.

RoHDE, E. (1921, 7 $/ 8^{\mathrm{a}}$ ed.), Psyche. Seelencult und Unsterblichkeitsglaube der Griechen. Vol. 1. Tübingen.

Schlesier, R. (1993), "Mixtures of Masks: Maenads as Tragic Models", in T. H. Carpenter, C. A. Faraone (eds.), Masks of Dionysus. IthacaLondon: 89-114.

Segal, C. (1982), Dionysiac Poetics and Euripides' Bacchae. Princeton.

SEgal, C. (1985), "The Bacchae as Metatragedy", in P. Burian (ed.), Directions in Euripidean Criticism. A Collection of Essays. Durham: 156-173.

Torres Esbarranch, J. J. (2004), Diodoro de Sicilia. Biblioteca Histórica. Libros IV-VIII. Madrid.

Versnel, H. S. (1972), "IAKXO $\Sigma$. Some Remarks suggested by an unpublished Lekythos in the Villa Giulia", Talanta 4: 23-38.

West, M. L. (1978), Hesiod. Works and Days. Oxford. 
Wildberg, C. (2002), Hyperesie und Epiphanie. Ein Versuch über die Bedeutung der Götter in den Dramen des Euripides. München.

Winnington-Ingram, R. P. (1997, $2^{\mathrm{a}}$ ed.), Euripides and Dionysus. An Interpretation of the Bacchae. London (1948, $1^{\mathrm{a}}$ ed.). 